\title{
A Simulation Study on the Flow Effectiveness of DBR Scheduling
}

\author{
Horng-Chyi Horng and Kuo-Kai Chien
}

\begin{abstract}
Ability to quick respond to customer demands has been a key competition factor in global market. Traditionally, product cycle time, work-in-process (WIP), order tardiness, and customer' service levels are used to evaluate manufacturing systems' performance. However, with rapid technology development toward Industry 4.0, these indices are not enough and unable to provide both prompt and detailed information regarding how congestion the system is. This study simulates a metal processing company where as taking into account a new measurement index about material flow, called flow value. With proper simulation experiments, DBR (Drum-Buffer-Rope) scheduling performs better than hybrid push/pull in most performance indices including flow value. A sensitivity analysis is also provided to show the robustness of DBR scheduling with respect to various demand patterns.
\end{abstract}

Index Terms-DBR, flow value, hybrid push/pull, simulation.

\section{INTRODUCTION}

In today's ever-changing market demands, a company's competiveness relies on its ability to respond in time and in good service to customers' demands. This requires effectively optimized the limited resources under gradually increased pressure from competition. Traditionally, product cycle time, work-in-processes (WIPs), order tardiness, and customer' service levels are used to evaluate manufacturing systems' performance. However, with rapid technology development toward Industry 4.0, these indices are not enough and unable to provide both prompt and detailed information regarding how congestion the system is. Flow value [1] is a measure of the logistics performance of a production system, adopted in this study to evaluate the stagnation time of the production line in terms of the quantity and cycle time of the products. In this study, using metal industry as an example, simulation models constructed from ARENA ${ }^{\circledR}$ software are validated and used as platform to examine the effectiveness of DBR (Drum-Buffer-Rope) scheduling over push/pull hybrid approach.

Pull production system is a key to realize lean manufacturing. Unlike push production system, widely adopted in the era of mass production, that pushes material and semi-finished products to the next station toward the end of production line, pull production system moves material and semi-finished product in time to the next station whenever needed. Smalley [2] mentioned that there are three types of

Manuscript received November 20, 2016; revised March 13, 2017.

Horng-Chyi Horng is with the Chaoyang University of Technology Technology, Taichung, 41349 Taiwan (e-mail: hchorng@ cyut.edu.tw).

Kuo-Kai Chien is with the Department of Industrial Engineering and Management, Chaoyang University of Technology, Taichung, 41349 Taiwan (e-mail: kcae86@yahoo.com.tw). pull systems, that is, supermarket, sequential, and mixed supermarket and sequential pull systems. In addition, Spearman [3] proposed a CONWIP (constant WIPs) where total number of WIPs are held constant all the time. Each of these four types of pull system has its own strength and adequate field of application. Among them, CONWIP is the most simplified control mechanism that Eng and Sin [4] recommended it for its easy-to-implement. Gastermann [5] also showed that CONWIP can significantly reduce production cycle time.

Theory of constraints(TOC) [6], [7] is a management paradigm introduced in 1984 based on the principle that a system's performance is limited by at least one constraint. TOC has been applied to fields such as marketing, sales, finance, and particularly operations management. When applied to operations management, a methodology called drum-buffer-rope(DBR) [8] is derived from the principle of TOC. The relation of TOC and DBR is similar to JIT(Just-in-time) and pull system (via Kanban). Both TOC and JIT are key methodology toward the development of today's lean manufacturing. There also is a simplified DBR(S-DBR) [9], [10], where the rope spans the entire production system just like CONWIP does in a pull system. Many applications of S-DBR in the literature including Lee and $e t a l$. [11] in which an enhanced using novel generic procedures is proposed to increase S-DBR's effectiveness.

Huff [12] quoted several studies that DBR outperform JIT in the following categories:

1) DBR required less inventory lowering manufacturing costs.

2) DBR had better customer requirement responsiveness.

3) DBR provided an opportunity for better product quality.

4) DBR produced more products with a lower standard deviation of flow time helping to determine when the product would be ready for shipment.

5) DBR results in lower WIP inventory which lowers investment in manufacturing costs.

Roser [13], on the other hand, preferred kanban system and CONWIP over DBR and pointed out several drawbacks of DBR as listed below:

1) DBR took no consideration for shifting bottlenecks.

2) DBR considered only starving of the bottleneck, not blocking.

3) DBR only cared about upstream inventory.

4) DBR provided no guidance on which part to produce next when there are multiple product variants in the system.

5) DBR had less flexibility in line management with only one loop.

6) DBR was less popular recently.

In this study, a complete simulation study with sensitivity 
analysis is conducted on a multiple product variants manufacturing system to evaluate the performance of DBR and hybrid push/pull while taking into account a new measurement index called flow value.

\section{MethodOLOGY}

\section{A. Research Methodology}

Fig. 1 illustrates the methodology used in this study. Firstly, related literature is reviewed as outlined in the previous section. A manufacturing company is then selected as case study in which at least two different types of product are produced simultaneously. In this study, ARENA ${ }^{\circledR}$ is adopted as simulation package to build models and realize hybrid push/pull mechanism as well as DBR scheduling. The simulation model for the as-is hybrid push/pull mechanism is constructed and then validated as well as verified before model building for DBR scheduling. There are two simulation experiments designed. One is a simulation study on the optimal demand pull period for the as-is system; the other is a simulation comparison on the performance between the as-is hybrid push/pull and the proposed DBR scheduling. Finally, a complete simulation output analysis is followed by conclusions and recommendations of this study.

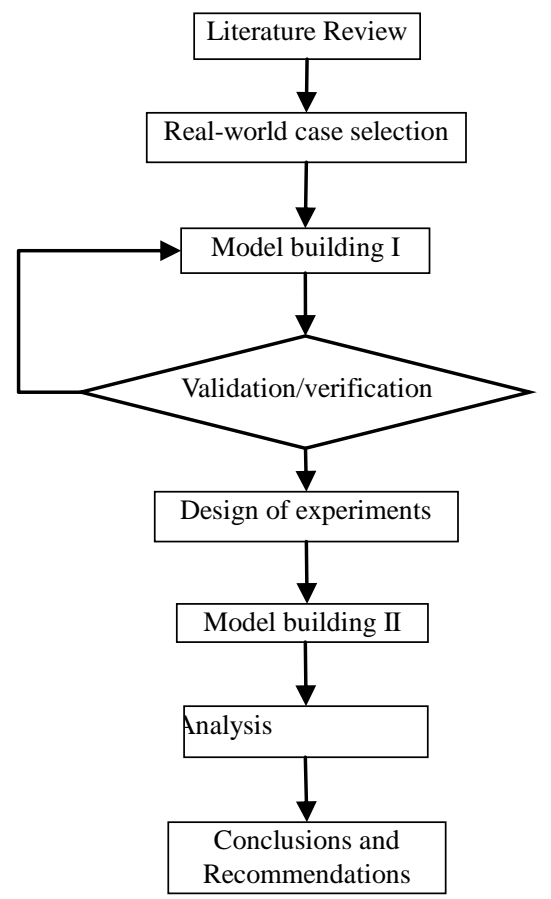

Fig. 1. The methodology.

\section{B. The Real-World Case}

A metal processing company manufactures sport bar and flat bar, and deliver them to bicycle assembly companies. In order to quick respond to customer demand, it applies a hybrid push/pull production mechanism. As depicted in Fig. 2 , production scheduling for processes before and including anodizing is based on demand forecasting and using push approach. The semi-products after anodizing are stored in the warehouse until customer orders comes in. Once there is a customer order, a demand pull production control is triggered to pull semi-products through the remaining three processes, that is, laser engraving, labelling, and assembling. This hybrid push/pull production mechanism is a modified approach from traditional make-to-order (MTO) push approach, and indeed improves customer satisfaction on order delivery efficiency. However, an unsatisfactory level of WIPs has bothered management staff as usual.

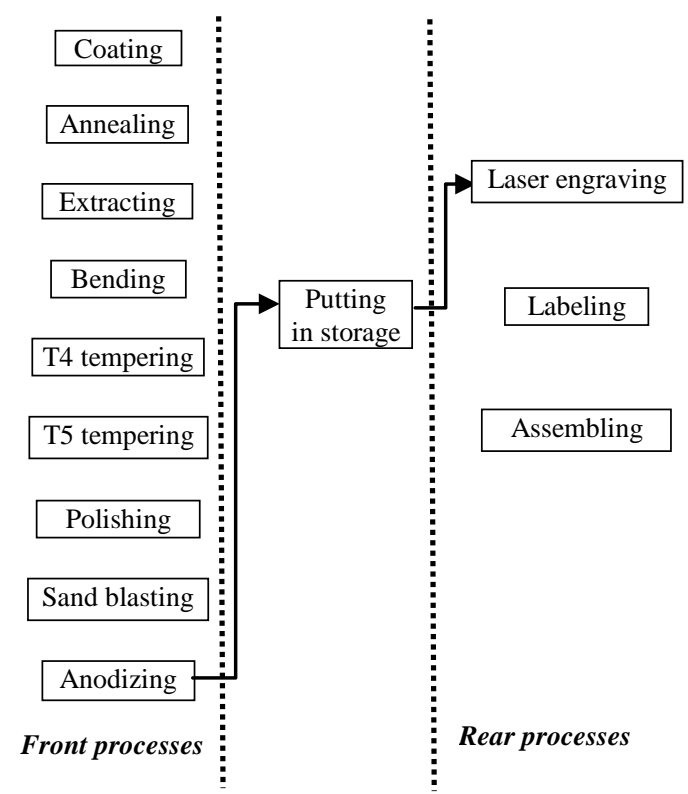

Fig. 2. Manufacturing processes of the real-world case.

\section{Model Building and Validation}

Currently, the process of anodizing is done by out sourcing companies. For anodizing, the number of resource in Table I is neglected while the processing time is the estimated cycle time of the outsourcing process including times for processing, inspection, and delivering.

\begin{tabular}{|c|c|c|c|}
\hline \multicolumn{4}{|c|}{ TABLE I: PROCESS PARAMETERS } \\
\hline \multirow[t]{2}{*}{ Process } & \multicolumn{2}{|c|}{$\begin{array}{l}\text { Process time (triangular } \\
\text { distribution,in Min.) }\end{array}$} & \multirow[t]{2}{*}{$\begin{array}{l}\text { Number of } \\
\text { resource }\end{array}$} \\
\hline & SportBar & FlatBar & \\
\hline Coating & \multicolumn{2}{|c|}{$(15,20,25)$} & 2 \\
\hline Annealing & \multicolumn{2}{|c|}{$(190,200,210)$} & 1 \\
\hline Extracting & \multicolumn{2}{|c|}{$(110,130,150)$} & 10 \\
\hline Bending & $(370,400,430)$ & $(53,73,39)$ & 5 \\
\hline T4 Tempering & \multicolumn{2}{|c|}{$(370,380,390)$} & 1 \\
\hline T5 Tempering & \multicolumn{2}{|c|}{$(420,440,460)$} & 1 \\
\hline Polishing & \multicolumn{2}{|c|}{$(155,165,175)$} & 5 \\
\hline Sand blasting & \multicolumn{2}{|c|}{$(15,18,21)$} & 2 \\
\hline Anodizng & \multicolumn{2}{|c|}{$(480)$} & - \\
\hline Laser engraving & \multicolumn{2}{|c|}{$(50,55,60)$} & 4 \\
\hline Labeling & \multicolumn{2}{|c|}{$(28,300,320)$} & 10 \\
\hline Assembling & \multicolumn{2}{|c|}{$(50,55,60)$} & 6 \\
\hline
\end{tabular}

Fig. 3 is the ARENA model of the as-is hybrid push/pull system. A total of 30 daily simulation throughputs is compared statistically to the actual 30 daily productions of two types of product, that is, sport bas and flat bar. Table II is the statistical test results and shows that there is no significant difference between simulation output and real production data. 

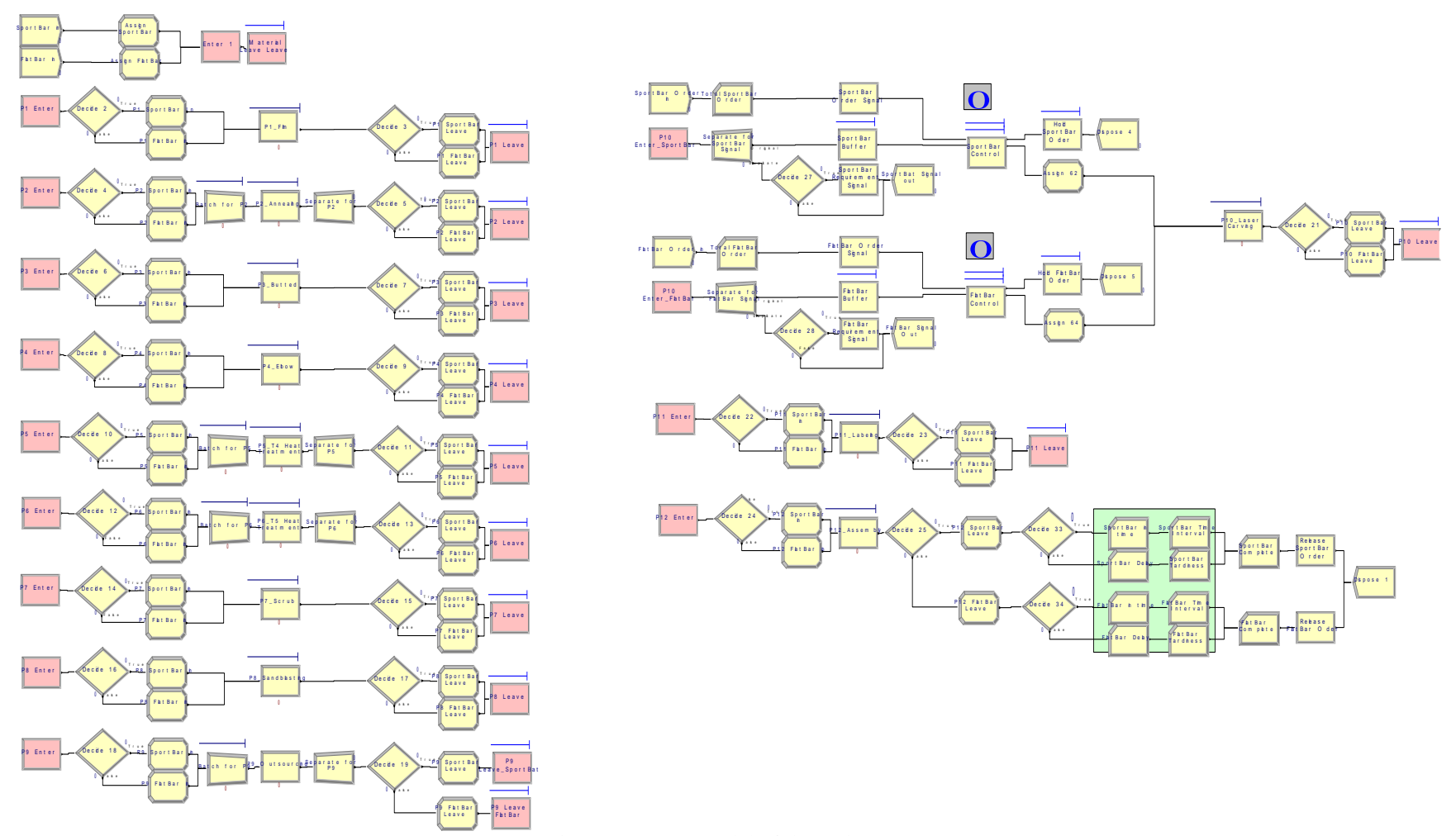

Fig. 3. ARENA model of the as-is system.

TABLE II: MODEL VALIDATION

\begin{tabular}{|c|c|c|c|c|}
\hline \multicolumn{3}{|c|}{ t test: Sport bar } & \multicolumn{2}{c|}{ t test: Flat bar } \\
\hline & Real-world & Simulation & Real-world & Simulation \\
\hline Mean & 193.267 & 196.800 & 651.169 & 653.033 \\
\hline Variance & 2449.789 & 454.510 & 13483.708 & 2322.447 \\
\hline d.f. & 29 & & 29 & \\
\hline$t_{0}$ & -0.359 & & -0.081 & \\
\hline P-value & 0.721 & & 0.936 & \\
\hline
\end{tabular}

\section{Flow Value}

In addition to commonly used performance measurements such as product cycle time, order completion time, tardiness, number of tardy unit, and percentage of tardy unit, this study adopts a new measurement called flow value. Flow value (Lin, 2016) [1] is a measure of the logistics performance of a production system, adopted in this study to evaluate the stagnation time of the production line in terms of the quantity and cycle time of the products. The stagnation time of a mixed-product production line is defined as $D$ in (1). Where $W I P_{i j}$ represents WIPs of product $j$ in process $i$ and $C T_{i j}$ represents cycle time of product $j$ in process $i$. The flow value for a mixed-product production line is thus defined as in (2). A flow value of one is the ideal status where no material stagnation at all in the production line. The greater the flow value, the more severe the material stagnation problem is.

$$
\begin{gathered}
D=\sum_{i} \sum_{j}\left(W I I_{i j} \times C T_{i j}\right) \\
F=\frac{D}{\sum_{i} \sum_{j} C T_{i j}}
\end{gathered}
$$

\section{DESIGN OF EXPERIMENTS}

Before comparing the effectiveness of the as-is hybrid push/pull to that of DBR scheduling, a study on the optimal order release period needs to be done. The current order release period is 5 working days (one week), that is, customer orders are cumulated for 5 days before released to the production line for a pull production on the rear portion of the entire manufacturing process. Therefore, there are two simulation experiments conducted in successive:

1) A simulation experiment designed to determine the optimal order release period for the as-in hybrid push/pull production.

2) Once optimal order release period is found, it is employed to conduct a simulation comparison experiment on the effectiveness of the as-is hybrid push/pull and DBR scheduling approach.

On both experiments, 30 replications of the length of 25 days, excluding 5 days for system warm-up, are conducted to generate enough simulation output for comparison. A sensitivity analysis on the order demand patterns is then performed to check sensitivity of our findings draw from the second experiment.

\section{FINDINGS}

\section{A. Experiment I}

A simulation experiment designed to determine the optimal order release period for the as-in hybrid push/pull production. The current order release period is 5 working days (one week), therefore, a single factor design with release period set at 1,2 , 5, 8, 12, and 25 days is conducted. Fig. 4 and Fig. 5 are the simulation output of this experiment in terms of total times and flow time, respectively. Corresponding simulation output data are listed in Table III and IV. There are two total times, one is order total time which measures the time between customer placed an order and goods for this order ready to be 
shipped to customer; the other is product total time which measures the cycle time of product in the manufacturing system. As clearly shown on Fig. 4, there is a steeper increase on the order total time when order release period is greater than 5 days. On the other hand, product total time is relatively steady for order release period set between 2 to 12.5 days. Referred to Table III, in order to minimize both order total time and product total time, the adequate order release period should be between 2 to 5 days.

Fig. 5 shows that no matter what product, sport bar or flat bar, WIPs decrease as order release period getting longer. On the contrary, flow value for the rear portion of the entire processes on Fig. 5 reveals almost the same pattern as order total time on Fig. 4, except when order release period is equal to 25 days. Comparing data patterns listed in Table III and IV, flow value is a better performance measurement than WIPs in reflecting material flow of the production since its value is proportion to order total time. Order tardiness in Table. V shows that when order release period is set to 1 or 25 days will incur tardiness on customer orders, therefore the best choice of order release period is either 2 or 3 days.

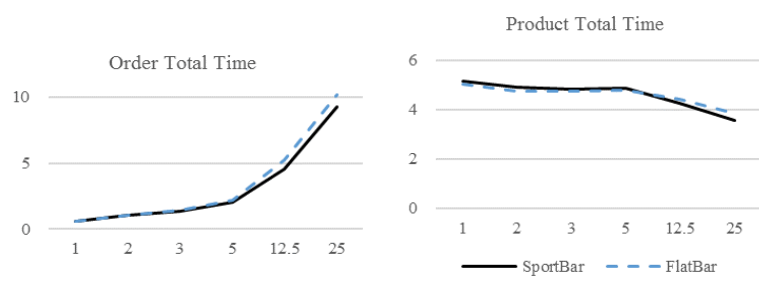

Fig. 4. Total times for different order release periods.

TABLE III: TOTAL TIMES FOR EXPERIMENT I

\begin{tabular}{|c|c|c|c|c|}
\hline \multirow{2}{*}{$\begin{array}{c}\text { Order Release } \\
\text { Period }\end{array}$} & $\begin{array}{c}\text { Product Total Time } \\
\text { (Day) }\end{array}$ & $\begin{array}{c}\text { Order Total Time } \\
\text { (Day) }\end{array}$ \\
\cline { 2 - 5 } & SportBar & FlatBar & SportBar & FlatBar \\
\hline $\mathbf{1}$ & 5.161 & 5.013 & 0.606 & 0.628 \\
\hline $\mathbf{2}$ & 4.889 & 4.763 & 1.027 & 1.021 \\
\hline $\mathbf{3}$ & 4.807 & 4.754 & 1.337 & 1.421 \\
\hline $\mathbf{5}$ & 4.851 & 4.802 & 2.075 & 2.224 \\
\hline $\mathbf{1 2 . 5}$ & 4.246 & 4.418 & 4.539 & 5.252 \\
\hline $\mathbf{2 5}$ & 3.578 & 3.828 & 9.246 & 10.176 \\
\hline
\end{tabular}

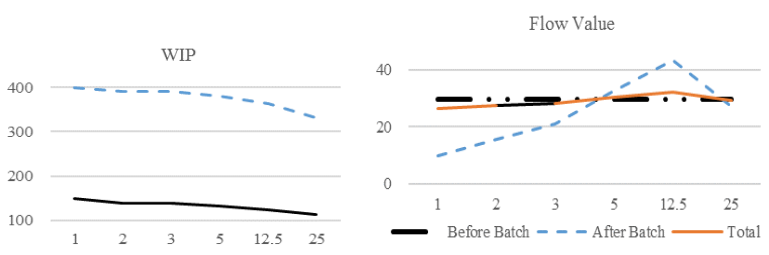

Fig. 5. Flow values for different order release periods.

TABLE IV: TARDINESS RELATED PERFORMANCE FOR EXPERIMENT I

\begin{tabular}{|c|c|c|c|c|c|}
\hline $\begin{array}{c}\text { Order } \\
\text { Release } \\
\text { Period }\end{array}$ & \multicolumn{2}{|c|}{ WIP } & \multicolumn{3}{c|}{ F-Value } \\
\cline { 2 - 6 } & SportBar & FlatBar & Front & Rear & Total \\
\hline $\mathbf{1}$ & 149 & 400 & 29.736 & 9.841 & 26.373 \\
\hline $\mathbf{2}$ & 139 & 390 & 29.691 & 15.697 & 27.329 \\
\hline $\mathbf{3}$ & 138 & 392 & 29.652 & 21.094 & 28.213 \\
\hline $\mathbf{5}$ & 133 & 381 & 29.635 & 32.657 & 30.162 \\
\hline $\mathbf{1 2 . 5}$ & 123 & 363 & 29.681 & 43.334 & 32.011 \\
\hline $\mathbf{2 5}$ & 113 & 331 & 29.637 & 27.113 & 29.221 \\
\hline
\end{tabular}

TABLE V: TARDINESS RELATED PERFORMANCE FOR EXPERIMENT I

\begin{tabular}{|c|c|c|c|c|c|c|}
\hline \multirow{2}{*}{$\begin{array}{c}\text { Order } \\
\text { Release } \\
\text { Period }\end{array}$} & $\begin{array}{c}\text { Tardiness Time } \\
\text { (Day) }\end{array}$ & \multicolumn{2}{c|}{ Tardiness Unit } & \multicolumn{2}{c|}{$\begin{array}{c}\text { \% of Run with } \\
\text { Tardy Unit }\end{array}$} \\
\cline { 2 - 7 } & SportBar & FlatBar & SportBar & FlatBar & SportBar & FlatBar \\
\hline $\mathbf{1}$ & 0.051 & 0.021 & 6 & 4 & $20.0 \%$ & $43.3 \%$ \\
\hline $\mathbf{2}$ & -- & -- & -- & -- & $0.0 \%$ & $0.0 \%$ \\
\hline $\mathbf{3}$ & -- & -- & -- & -- & $0.0 \%$ & $0.0 \%$ \\
\hline $\mathbf{5}$ & -- & -- & -- & -- & $0.0 \%$ & $0.0 \%$ \\
\hline $\mathbf{1 2 . 5}$ & -- & -- & -- & -- & $0.0 \%$ & $0.0 \%$ \\
\hline $\mathbf{2 5}$ & 0.910 & 0.214 & 20 & 12 & $10.0 \%$ & $13.3 \%$ \\
\hline
\end{tabular}

\section{B. Experiment II}

Once optimal order release period is found, it is employed to conduct a simulation comparison experiment on the effectiveness of the as-is hybrid push/pull and DBR scheduling approach. In this stage of simulation study, order release period of 2 and 3 days are both employed because their performance measurements in experiment I are not all significant difference. In DBR scheduling, semi-products are pulled to avoid the bottleneck process become starved, and then push throughout the remaining processes. In this study, DBR scheduling is applied to the front portion of manufacturing processes where push mechanism is originally used. The pull part of the as-is hybrid push/pull production is remaining unchanged.

TABLE VI: TOTAL TIMES OF EXPERIMENT II

\begin{tabular}{|c|c|c|c|c|c|}
\hline \multirow{2}{*}{$\begin{array}{c}\text { Order } \\
\text { Release } \\
\text { Period }\end{array}$} & $\begin{array}{c}\text { Product Total Time } \\
\text { (Day) }\end{array}$ & $\begin{array}{c}\text { Order Total Time } \\
\text { (Day) }\end{array}$ \\
\cline { 3 - 6 } & SportBar* & $\begin{array}{c}\text { FlatBar } \\
*\end{array}$ & $\begin{array}{c}\text { SportBa } \\
\mathbf{r}\end{array}$ & $\begin{array}{c}\text { FlatBa } \\
\mathbf{r}\end{array}$ \\
\hline \multirow{2}{*}{$\mathbf{2}$} & Original & 4.889 & 4.763 & 1.027 & 1.021 \\
\cline { 3 - 6 } & DBR & 2.759 & 3.613 & 1.171 & 1.038 \\
\hline \multirow{2}{*}{$\mathbf{3}$} & Original & 4.807 & 4.754 & 1.337 & 1.421 \\
\cline { 2 - 6 } & DBR & 2.904 & 3.745 & 2.582 & 1.312 \\
\hline
\end{tabular}

In Table VI lists simulation output related to total times for order release period of 2 and 3 days. It shows that with DBR, product total times are significantly reduced. On the other hand, order total times do not differ significantly. Table VII offers logistic related performance, that is, WIPs and flow value. The effectiveness of DBR scheduling is strongly supported by statistically significant reductions in both WIPs and flow values. Simulation results show no existence of order tardiness.

TABLE VII: WIPS AND FLOW VALUE OF EXPERIMENT II
\begin{tabular}{|c|c|c|c|c|c|c|}
\hline \multirow{2}{*}{$\begin{array}{c}\text { Order } \\
\text { Release } \\
\text { Period }\end{array}$} & \multicolumn{2}{|c|}{ WIPs } & \multicolumn{3}{|c|}{ Flow Value } \\
\cline { 2 - 7 } & SportBar* & FlatBar* & Front* & Rear* & Total* \\
\hline 2 & Original & 139 & 390 & 29.691 & 15.697 & 27.329 \\
\cline { 2 - 7 } & DBR & 45 & 194 & 12.882 & 10.938 & 12.515 \\
\hline \multirow{2}{*}{3} & Original & 138 & 392 & 29.652 & 21.094 & 28.213 \\
\cline { 2 - 7 } & DBR & 44 & 196 & 13.374 & 12.966 & 13.336 \\
\hline
\end{tabular}

\section{Sensitivity Analysis}

A sensitivity analysis is conducted on the different demand patterns. There are three demand patterns drawn from different probability distributions, that is, Triangular, Poisson, and Uniform, with respect to three level of demand variations. 


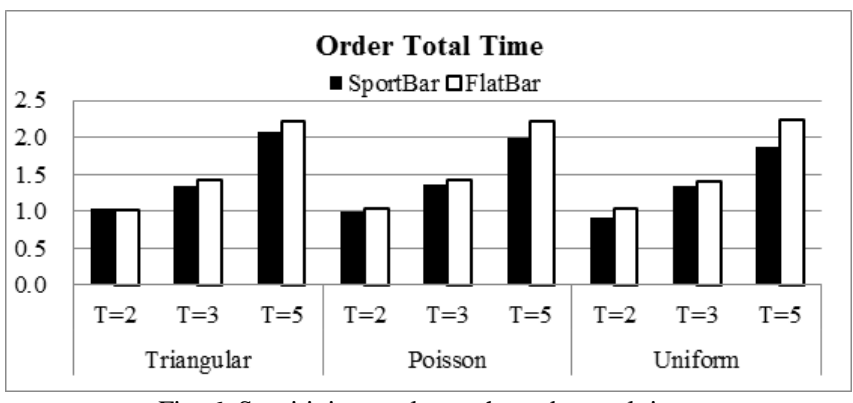

Fig. 6. Sensitivity results on the order total time.

\section{CONCLUSIONS AND RECOMMENDATIONS}

In this study, using metal industry as an example, simulation models constructed from ARENA ${ }^{\circledR}$ software are validated and used as platform to examine the effectiveness of DBR scheduling over push/pull hybrid approach. Several conclusions and recommendations can be drawn from simulation experiments, and listed below:

1) Employing hybrid push/pull production mechanism indeed improve system's performances in terms of total times and WIPs. However, optimal selection of order release period needs to be evaluated to achieve better performance. In the case study, order total time decreases $35 \%$ to $50 \%$ depending on product type only by shifting order release from the original 5-day period to 2 - or 3-day period.

2) Applying DBR scheduling to the front portion of manufacturing processes can further improve logistic related performance measurements such as WIPs and flow value. It cuts WIPs into half, and improves flow value for nearly $150 \%$.

3) As findings discussed in experiment I, flow value is a better performance measurement than WIPs in reflecting material flow of the production since its value is proportion to order total time.

4) S-DBR is a simplified version of DBR. Future studies are encouraged to examine S-DBR's effectiveness when applying to a mixed product system.

5) Flow value can reflect what's really going on in the logistic portion of the production system. More studies are encouraged to focus on its applications.

\section{REFERENCES}

[1] L. Y. Lin, "A research on performance indicator of material flow for production systems," Master thesis, Dept. IE\&M, Chaoyang Univ. of Tech., Taichung, Taiwan, 2016.

[2] A. Smalley, Creating Level Pull, Lean Enterprise Institute, 2007.

[3] M. L. Spearman, D. L. Woodruff, and W. J. Hopp, "CONWIP: A Pull alternative to Kanban," Int. J. of Prod. Res., vol. 28, pp. 879-894, 1990.

[4] C. K. Eng and L. K. Sin, "CONWIP based control of a semiconductor end of line assembly," Procedia Eng., vol. 53, pp. 607-615, 2013.

[5] B. Gastermann, M. Stopper, F. Luftensteiner, and B. Katalinic, "Implementation of a software prototype with Con WIP characteristics for production planning and stock management," Procedia Eng., vol. 69, pp. 423-432, 2014.

[6] E. M. Goldratt, Theory of Constraints, Great Barrington, MA: North River Press, 1984.

[7] J. Cox and E. M. Goldratt, The Goal: A Process of Ongoing Improvement, Croton-on-Huson, NY: North River Press, 1986.

[8] E. M. Goldratt and R. Fox, The Race, Croton-on-Huson, NY: North River Press, 1986.

[9] E. Schragenheim and H. W. Dettmer, Manufacturing at Warp Speed: Optimizing Supply Chain Financial Performance, Boca Raton, FL: St. Licie Press, 2000.

[10] E. Schragenheim, A. Weisenstern, and A. Schragenheim, "What's really new in simplified DBR," presented at TOCICO International Conference, Las Vegas, NV, 2006.

[11] J. H. Lee, J. G. Chang, C. H. Tsai, and R. W. Li, "Research on enhancement of TOC simplified drum-buffer-rope system using novel generic procedure," Expert Systems with Application, vol. 37, pp. 3747-3754, 2010.

[12] P. Huff, "Using dram-buffer-rope scheduling rather than just-in-time production," Management Accounting Quarterly, winter, pp. 36-40, 2001.

[13] C. Roser. (2014). A critical look at Goldratt's drum-buffer-rope method. [Online]. Available: http://www.allaboutlean.com/drum-buffer-rope/

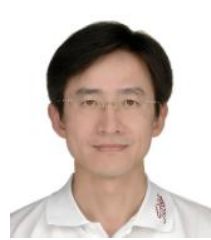

Horng-Chyi Horng was born in Taichung, Taiwan in 1966. He came to USA in 1991 and got his M.S.E and Ph.D. degrees from the Department of I\&MSE at Arizona State University, in 1992 and 1996, respectively. His major field of study is systems simulation.

He used to work as a systems engineer at KEEKOR Environmental Product, Inc. from 1994 to 1996. After graduated from ASU in 1996, he returned to Taiwan and got an ASSOCIATE PROFESSOR faculty position at Chaoyang University of Technology. He currently serves as the chairperson for the department of Industrial Engineering and Management. His research interests include systems simulation, quality control, and decision sciences. 